Sris 3

(1832-1850)

\title{
natom
}

\section{On sulphipianic acid}

\section{Wöhler}

To cite this article: M. Wöhler (1845) On sulphipianic acid, Philosophical Magazine Series 3, 26:170, 79-80, DOI: 10.1080/14786444508645072

To link to this article: http://dx.doi.org/10.1080/14786444508645072

曲 Published online: 30 Apr 2009.

Submit your article to this journal 주다

LII Article views: 3

Q View related articles $₫$ 
The conclusion arrived at is, that the mode of estimating the force of evidence employed in a court is a process which algebraic investigation analyses, and of which it explains the theory, and an approximation to a result which is obtained with accuracy by assigning numerical values to the algebraic symbols : a clear conception of the nature of the practical process, it is conceived, must render its application more accurate, and to the extent of affording this the investigation is deemed to be of practical utility.

\section{Intelligence and Miscellaneous Articles.}

ON SULPHIPIANIC ACID. BY M, WÖHLER.

THIS acid is formed by the action of sulphurous acid upon opianic acid, which dissolves in considerable quantity in a hot solution of sulphurous acid, without being deposited on cooling; this solution has a peculiar bitter taste and a sweetish after-taste; the carbonates of barytes and lead dissolve in it and form well-crystallized salts.

When the solution of opianic acid in sulphurous acid is evaporated at a moderate temperature, the sulphipianic acid remains in the state of a transparent crystalline mass : this mass is usually rather moist, because it accidentally contains a little sulphuric acid, but none is ever found in the recently-prepared solution. It is colourless, and on the addition of water it becomes milky, and acquires a strong odour of sulphurous acid; the white substance which separates is opianic acid: the new acid therefore, when in a crystalline state, is decomposed by water into opianic and sulphurous acid, but it talses place only partially.

The analyses of the salts of barytes and lead showed that the sulphipianic acid may be represented by $\mathrm{C}^{20} \mathrm{H}^{6} \mathrm{O}^{7} \mathrm{~S}^{2}$. It was requisite to analyse these salts after drying at the usual temperature, and consequently retaining their water of crystallization, a portion of which they lose at a slight increase of temperature, whereas a further quantity is not expelled till the salt begins to decompose. Nitric acid does not separate the aeid from these salts, chlorine decomposes them slowly and incompletely: the quantity of sulphur was determined by calcination in a tube with a mixture of carbonate of soda and nitre.

The sulphipianate of lead contained-

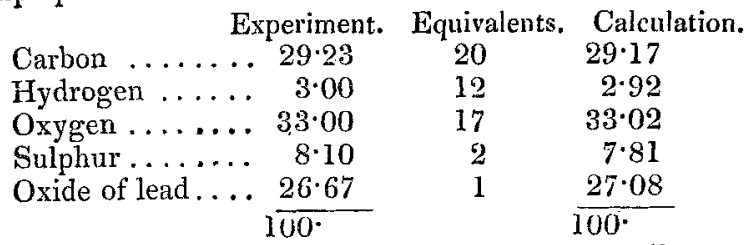

Calculation corresponds to the formula $\mathrm{Pb}+\mathrm{C}^{\circ 0} \underline{\mathrm{H}}^{6} \mathrm{O}^{7} \ddot{\mathrm{S}}^{2}+6 \underline{\mathrm{HO}}$. The six equivalents of water which are expelled at $338^{\circ} \mathrm{F}$. correspond to $13 \cdot 10$ per cent.; experiment gave $13 \cdot 68$.

The salt of lead crystallizes in four-sided prisms, but the crystals 
are usually in the form of six-sided tables. This salt undergoes no change by exposure to the air; at $212^{\circ}$ it becomes opake but does not effloresce; it then becomes yellow in the light. When moderately heated it loses 3 equivalents, or half its water of crystallization, and the remaining 3 are expelled at a higher temperature, but it becomes yellow and continues to smell; at a still higher temperature it fuses and loses much sulphurous acid.

The barytic salt crystallizes in rhombic tables which are colourless and brilliant. It dissolves slowly in water; it loses all its water of. crystallization at a high temperature, becomes opake and begins to decompose. It contains 3 equivalents of water.

M. Wöhler states that he shall hereafter consider the formation and composition of this acid, as to whether it should be considered to contain 1 equivalent of hyposulphuric acid or 2 equivalents of sulphurous acid. The mode in which it is acted upon by water favours the latter view, and its action on selenious acid also supports it. When it is employed alone it is not altered by it; but by admix ture with hydrochloric acid, the selenious acid is reduced. When the acid is mixed with chloride of gold, there separate, after some time, opianic acid and reduced gold in brilliant tables.-Ann. de Ch. et de Phys., Octobre 1844.

\section{ON SULPHOPIANIC ACID.}

$M$. Wöhler gives this name to the acid produced by the action of sulphuretted hydrogen on opianic acid.

When sulphuretted hydrogen gas is passed into a boiling solution of opianic acid, no visible action occurs; but if the temperature be considerably reduced, the liquor luses its transparency, and a precipitate resembling sulphur is formed, the quantity of which goes on increasing. By these means all the opianic acid is converted into this new compound, but the change occupies several days. If the mixture be heated to ebullition, the yellow precipitate disappears, and is converted into a liquid of the same colour, which soon falls to the bottom of the vessel, where it becomes solid on cooling.

Sulphopianic acid thus obtained is an amorphous transparent mass of a sulphur-yellow colour, which liquefies at $212^{\circ}$. If it be more strongly heated, it decomposes, emitting a yellowish vapour which condenses in fine crystalline needles; these burn with flame and evolve sulphurous acid; they are insoluble in water, but dissolve readily in alcohol, to which they impart a yellow colour. If the acid has been fused previously to being dissolved in the alcohol, an amorphous transparent mass merely is obtained by spontaneous evaporation; but if in the preparation of the acid the heat has been so managed as to prevent its fusion, it is then obtained in the state of small transparent crystals, which when collected have a yellow colour. This acid therefore undergoes by fusion a change analogous to that which opianic acid suffers under similar circumstances. Concentrated sulphuric dissolves it and becomes yellow, and when heated of a deep purple. Chlorine and the alkaline hypochlorites oxidize the sulphur which it contains slowly and imperfectly; the alkalies dis- 